\title{
A doçaria paulista no início do século XX
}

\section{Sweets consumption in São Paulo in the early $20^{\text {th }}$ century}

Paola Biselli Ferreira Scheliga ${ }^{1}$

Esta pesquisa discute a mudança de hábitos alimentares voltados ao consumo de doces no processo de urbanização da cidade de São Paulo entre o final do século XIX e o início do século XX.

Através de uma abordagem qualitativa, o estudo faz um levantamento bibliográfico teórico-reflexivo tanto dos autores basilares sobre a alimentação no Brasil, bem como acompanha historicamente a formação da doçaria nacional e seu desenvolvimento. Esse esforço culmina com um aprofundamento sobre a doçaria caipira com suas raízes já não mais comuns na cidade de São Paulo.

Por fim, através de uma abordagem quantitativa e também qualitativa, foram focalizados cinco livros de receitas publicados entre 1910 e 1930, como fontes para os estudos da alimentação com o objetivo de compreender a doçaria paulista no início do século XX. O resultado foi uma base de dados de 700 receitas para identificação dos principais ingredientes utilizados. Os livros selecionados foram: A sciencia no lar moderno (1912), Delícias das sinhás: receitas culinárias da segunda metade do século XIX e início do século XX (2007), Culinária tradicional do Vale do Paraíba (1992), A doceira paulista (1916), Guia prático da doceira (1930).

De acordo com a análise realizada é possível perceber uma forte influência da confeitaria tradicional portuguesa. A partir do levantamento de receitas realizado, foi possível perceber a predominância de ingredientes como a farinha de trigo, os ovos, a manteiga, a canela, o cravo e a amêndoa. Todos estes ingredientes são muito utilizados na doçaria tradicional portuguesa.

Poucas foram as referências encontradas nos livros que remetem aos ingredientes reconhecidos como base da alimentação caipira, como o milho, o amendoim, a mandioca, a abóbora, entre outros. Os estudos sobre o caipira são muito mais aprofundados em relação a seus hábitos culturais, sua formação étnica, peculiaridades sobre a sua linguagem do que sobre os hábitos alimentares propriamente ditos. Há uma carência de material específico sobre a doçaria caipira e isto está diretamente relacionado à perda de referências e tradições.

Mais do que definir quais as principais influências na culinária paulista do início do século $X X$, este trabalho traz a conclusão de que outros caminhos de pesquisa podem ser utilizados para estudos sobre cultura material e cultura alimentar brasileiras ainda pouco explorados. A busca por novas fontes de pesquisa pode trazer resultados diferentes do esperado e propiciar um novo entendimento sobre a formação cultural da sociedade paulistana.

Palavras-chave: doçaria; caipira; cultura; Belle époque paulistana.

Keywords: sweets; caipira; culture; Belle époque in the city of São Paulo.

1 Mestre em Educação, Arte e História da Cultura pela Universidade Presbiteriana Mackenzie, docente e pesquisadora no curso de Gastronomia da Universidade Presbiteriana Mackenzie. 